\title{
Observational learning in hooded rats
}

\author{
JON DEL RUSSO* \\ George Washington University, Washington, D.C. 20006
}

Three groups of rats, six Ss to a group, were tested to determine the effect of reinforced and nonreinforced observation on the learning of a leverpressing response. Group 1 observed a leverpressing response while receiving food contingent on the model's responses; Group 2 observed the leverpressing response without receiving food; and Group 3 , the control group, did not observe the model's performance. The three groups were subsequently tested in an operant conditioning situation. Group 1 proved significantly superior to Groups 2 and 3 in time to acquisition of the observed response $(p<.004)$. The difference between Group 2 and the control group was not significant. The results were interpreted in terms of Mowrer's two-factor theory.

Numerous experiments with different species have been carried out to determine whether or not an animal more readily learns a response after observing another animal's performance of that response. Several such studies of observational learning in relatively advanced species have reported positive results. Warden \& Jackson (1939) found that rhesus monkeys exhibited high proficiency in the imitation of novel tasks observed. John et al (1968) tested cats in an avoidance situation in which the animals jumped over a hurdle to avoid shock and in another situation in which the cats pressed a lever for food. Observer cats, they report, learned both tasks significantly faster and with fewer errors than did cats conventionally trained. However, there is little evidence that a lower species, such as the rat, can benefit through observation. The present experiment was designed to help bridge this gap in the research on observational learning.

An additional factor tested in the present experiment was the role of reinforcement in learning through observation. Some Es have suggested that, in, certain cases, it may be necessary for the observer to experience the results of the act observed before imitation can occur (Miller \& Dollard, 1941; Berry, 1908). Berry found that kittens would not imitate a cat's killing of a mouse until the kitten had himself eaten the mouse he had observed being killed. Although it has been shown that direct extrinsic reinforcement is not necessary to observational learning in more advanced species (John et al, 1968; Warden \& Jackson, 1939), it was felt that reinforcement might be a significant factor in the learning of a species of a lower order such as the rat.

*'The author thanks Dr. John Bull of George Washington University for his assistance in preparing this manuscript for publication.

\section{SUBJECTS}

The Ss were 18 Long-Evans hooded rats between 150 and 200 days old. In addition, a trained rat of the same strain was used as a model.

\section{APPARATUS}

The training apparatus was constructed by attaching a wire observation cage with a transparent Plexiglas front to the side of a standard operant chamber of reduced width. An operant lever was available only to the model rat in the operant chamber but was visible to the observer rat. The lever was located 2 in. above the floor grid. The pressure required to depress the lever was $11 \mathrm{~g}$. Food pellets could be delivered to foodcups located in both the operant chamber and the observation cage, using standard pellet dispensers. The operant chamber foodcup was 1 in. to the left of the lever and $11 / 4 \mathrm{in}$. from the grid floor. The observation cage foodcup was located $1 \frac{1 / 2}{\mathrm{in}}$. to the right of the operant chamber lever and was separated from it by the Plexiglas window. The operant chamber was 5 in. wide $\times 9$ in. long $x 7$ in. high.

\section{PROCEDURE}

Fourteen days before the observation trials were begun, all Ss and the model were placed on a $23 \cdot \mathrm{h}$ food-deprivation schedule. At this time, the model was trained to press a lever for food using standard procedures. Additional periodic training sessions assured that a stable high level of performance (12-15 responses/minute) was maintained throughout the experiment.

The Ss were equally divided into three groups: a control group (C) and two experimental groups. In one experimental group (FOB), Ss received free pellets during observation trials, the delivery being contingent upon the model's responses. In the second experimental group $(O B)$, Ss were not given free pellets during observation trials.
On the day prior to the start of observation training, all Ss were given a $15-\mathrm{min}$ familiarization period in the observation box. Ten $37-\mathrm{mg}$ pellets were present in the observation cage foodcup, along with some powdered lab chow.

\section{OBSERVATION TRAINING FOB Group}

On the first day of training, each FOB $\mathrm{S}$ was placed in the observation box. The foodcup contained five pellets. While the FOB $S$ was eating the pellets, the $\mathrm{E}$ placed the model in the operant chamber. The model consistently began responding almost immediately. Both pellet dispensers were wired to deliver a food pellet contingently upon each response emitted by the model. After 55 responses, the model was removed to its cage. The FOB animals were transferred to the operant chamber for acquisition training.

\section{OB Group}

On the first day of training, the $O B$ $S$ was placed in the observation box. The foodcup contained five pellets. While the $O B$ animal was eating, the $E$ delivered 55 food pellets by operating the food magazine externally in order to equalize conditioning to the sound of the food magazine produced in the FOB group. The 55 pellets were delivered in a period of $41 / 2 \mathrm{~min}$, approximately the time it would have taken the model to respond 55 times and simulating the rate of delivery to the model. The observation box pellet dispenser was disconnected, and the model was then placed in the operant chamber, as above. The $O B$ animal could observe the model but was not fed during observation. After 55 observation trials, the model was removed and the OB $S$ was transferred to the operant chamber for acquisition testing.

\section{Control Group}

On the first day of training, the control $S$ was placed in the observation box. The foodcup contained five food pellets. While the $S$ was eating these pellets, the $\mathbf{E}$ delivered 55 food pellets, as in the OB training procedure. During the time the control $\mathbf{S}$ was in the observation box, the operant chamber was empty. After the 55 pellets were delivered to the control $S$, he was moved from the observation box to the operant chamber for acquisition testing. ACQUISITION TESTING

After three food pellets were placed in the foodcup, each experimental and control $S$ was transferred to the operant chamber for a 1-h test session. Ss were free to barpress for continuous food reinforcement. The entire observation training and acquisition testing procedure was repeated daily for all Ss until learning occurred or 
Table 1

Time (in Minutes) to Acquisition

\begin{tabular}{cccc}
\hline & $\begin{array}{c}\text { Control } \\
\text { Group }\end{array}$ & $\begin{array}{c}\text { OB } \\
\text { Group }\end{array}$ & $\begin{array}{r}\text { FOB } \\
\text { Group }\end{array}$ \\
\hline S1 & NL* & NL & 25 \\
S2 & NL & NL & 28 \\
S3 & NL & 188 & 45 \\
S4 & NL & 42 & 3 \\
S5 & 40 & 232 & 70 \\
S6 & NL & NL & 5 \\
\hline
\end{tabular}

*NL-no learning

until a 7-day limit was reached. If the learning criterion was achieved before 7 days, the training was terminated. The criteria for learning were (1) the animal had to eat the food which it received for responding, (2) the animal must have been responding at a relatively steady rate for at least $2 \mathrm{~min}$, and (3) at least 20 responses must have been made under the first two conditions stated. The E recorded response and interresponse times by use of a timer.

\section{RESULTS}

The time to acquisition is shown for the three groups in Table 1 . One of the control Ss and three of the OB Ss met the learning criterion, whereas all six FOB Ss learned the task. A Mann-Whitney $U$ test indicated that the FOB group was superior to both the control group $(p<.004)$ and the OB group $(p<.004)$ in acquiring the response. The difference between the $O B$ and $C$ groups was not significant. The scores of two of the FOB animals,
3 and $5 \mathrm{~min}$, indicate that very rapid acquisition of a leverpressing response is possible under conditions of observation

\section{DISCUSSION}

The results support the contention that observation trials can facilitate a rat's acquisition of an observed response when the observer receives model-contingent food reward during observation. Observation alone did not significantly affect subsequent learning of an observed response in the present experiment. To understand these results, the behavior of the rats under different conditions must be considered. The activity of the FOB and $O B$ groups was centered around the lever, whereas the control Ss paid no special attention to the lever. Two of the FOB Ss went immediately to the lever and began performing the response. These two animals seemed to have learned the response during the observation session. The other FOB Ss directed their activity at the lever, but the required response was not performed immediately. They bit the lever or attempted to push it upward, persisting in this activity until the response was learned. Thus observation appeared to direct the activity of FOB and OB Ss toward the lever, while the exact form of the observed response appeared to be learned largely through trial and error.

The main difference between $O B$ and FOB activity was that FOB Ss were more persistent in their activity with the lever than were $O B$ Ss. The three $O B$ Ss that failed to learn the response persisted in bar-directed activity for only a few minutes.

The results of this experiment are consistent with Mowrer's (1950) two-process analysis of observational learning. In the present experiment, the sight of the moving lever was contiguous with the reception of food pellets by the FOB Ss. By this pairing, the movement of the lever may have become a conditioned reinforcer. When the FOB Ss were placed into the conditioning box, the $S$ 's own activity directed at the lever caused the lever to move, producing the conditioned reinforcer which, in turn, strengthened leverpressing behavior. For OB Ss, sight of the moving lever and reception of food were not contiguous. The movement of the lever may not have become a conditioned reinforcer, so that self-produced movement of the lever was not so readily strengthened. This may account for the less persistent activity of the $O B$ group.

\section{REFERENCES}

BERRY, C. S. An experimental study of imitation in cats. Journal of Comparative Neurology, 1908, 18, 1-25.

JOHN, E. R. CHESLER, P. BARTLETT, F., \& VICTOR, I. Observational leaming in cats. Science, 1968, 159, 1489-1491.

MILLER, N. W., \& DOLLARD, J. Social learning and imitation. New Haven: Yale University Press, 1941

MOWRER, O. H. Learning theory and personality dynamics. New York: Ronald Press, 1950.

WARDEN, C. J. \& JACKSON, T. A. Imitative behavior in the rhesus monkey. Journal of Comparative Psychology, $1939,27,133-147$. 